\title{
PEREGRINAS, ANDARILHAS E AUTORAS: LEGADOS DE MARGERY KEMPE E TERESA D’ÁVILA
}

\section{PILGRIMS, WANDERERS AND AUTHORS: LEGACIES OF MARGERY KEMPE AND TERESA OF AVILA}

\author{
Maria Graciele de LIMA* \\ Fernanda Cardoso NUNES ${ }^{* *}$
}

\begin{abstract}
Resumo: Este trabalho objetiva apresentar as obras The Book of Margery Kempe, da mística inglesa Margery Kempe (século XV) e o Libro de las Fundaciones, da espanhola Teresa d'Ávila (século XVI), dois escritos que advêm de contextos literários medievais distintos: o inglês e o espanhol, respectivamente. Sob a temática que envolve a peregrinação, no primeiro caso, e a jornada de fundações de mosteiros que fizeram Teresa d'Ávila ser conhecida como uma andarilha, ambos os casos resultaram no desenvolvimento de uma obra narrativa peculiar e que dá a esse nicho da Literatura Medieval a consistência de uma tradição de autoria feminina, pois está relacionado a várias outras produções intelectuais realizadas por mulheres. Como fundamentação teórica para a análise dos referidos textos, em seus contextos, faremos uso dos estudos de Atkinson (1983), Morrison (2000), Telles (2017), Egido (2002) e de outros/as estudiosos/as que contribuem para o alargamento das discussões que serão desenvolvidas.
\end{abstract}

Palavras-chave: Literatura Medieval. Peregrinações. Andarilha. Margery Kempe. Teresa d'Ávila.

\begin{abstract}
This paper aims to present the works The Book of Margery Kempe, by Margery Kempe (15 century), and Libro de las Fundaciones, by Teresa of Avila ( $16^{\text {th }}$ century), two writings that come from different medieval literary contexts: English and Spanish ones, respectively. Under the theme that involves pilgrimage, in the case of Margery Kempe, and the journey of foundations of monasteries that made Teresa of Avila known as a wanderer, both cases resulted in the development of a peculiar narrative that gives this niche of Medieval Literature the consistency of a tradition of woman authorship, as it is related to several other intellectual productions made by women. Textual and contextual analyses are based on the studies of Atkinson (1983), Morrison (2000), Telles (2017), Egido (2002) and other scholars who contribute to the broadening of the discussions that will be developed.
\end{abstract}

Keywords: Medieval Literature. Pilgrimages. Wanderer. Margery Kempe. Teresa of Avila.

\footnotetext{
${ }^{*}$ Grupo de Pesquisa Christine de Pizan, CNPq/UFPB/UnB. Doutorado em Letras pelo Programa de Pós-Graduação em Letras da Universidade Federal da Paraíba (PPGL/UFPB), com período sanduíche na Universidad de Santiago de Compostela (Espanha). E-mail: gracieledelima@rocketmail.com. ORCID iD: https://orcid.org/0000-00027004-0337.

${ }^{* *}$ Professora Assistente da Universidade Estadual do Ceará (UECE-FAFIDAM). Doutoranda do Programa de Pósgraduação em Letras da Universidade Federal da Paraíba (PPGL/UFPB). E-mail: fernandacardosonunes@yahoo.com.br. ORCID iD: https://orcid.org/0000-0001-9405-1754.
} 


\section{Introdução}

Este artigo objetiva analisar a obra das autoras Margery Kempe (1373 - c. 1435) e Teresa d'Ávila (1515-1582) como peregrinas e escritoras. Viajar por motivos religiosos, o que constitui a jornada da peregrinação para mulheres e homens, é uma prática devocional dos primórdios da Cristandade. Visitar os locais onde Cristo e os apóstolos viveram, tocar as relíquias de mártires e santos se tornou uma forte experiência do Cristianismo medieval: "O peregrino, mais do que viajar, subordinava a organização da sua existência à viagem, confundindo esses dois planos - o de existir e o de viajar -, pois buscava não uma simples aproximação dos lugares pisados por Cristo ou consagrados pelos milagres, mas um retorno espiritual à casa de Deus.” (FRANÇA, 2017, p. 9). Apesar das restrições à circulação de mulheres na Idade Média ou da imposição da clausura de muitas, elas estavam entre os primeiros peregrinos cristãos.

A peregrinação a um lugar considerado sagrado poderia ser considerada uma espécie de iniciação a uma nova forma de ver a vida. A importância das peregrinações pode ser constatada nas várias menções feitas às mesmas nos textos de autoria feminina medievais. Mulheres peregrinas, como Egéria (século IV) deixaram obras que relatam suas viagens à Terra Santa. $\mathrm{O}$ Itinerário de Egéria (Itinerarium Egeriae ou Itinerarium Peregrinatio ad loca sancta), por exemplo, chegou até nós incompleto. Segundo alguns estudiosos, a obra foi escrita em latim vulgar e trata sobre a sociedade e as questões religiosas da época, relatando suas viagens a Constantinopla, a Jerusalém, à Capadócia, ao Alto Egito e ao Sinai. Os relatos foram escritos, provavelmente, entre os anos de 393 e 396, sendo de grande importância documental para se compreender aqueles primeiros séculos do cristianismo.

Como podemos destacar, o período denominado como "Idade Média" foi longo e cheio de variações no que se refere ao delineamento de valores e práticas sociais. O silêncio imposto às religiosas bem como a proteção das mulheres por meio da construção/doação de monastérios (medidas de Gregório Magno [540-604]) não configurou uma única realidade para as religiosas.

Durante os séculos VII e VIII foram construídas por todos os lados instituições femininas, e as mulheres conseguiram encontrar homens de religião que intercedessem por elas. Nos séculos IX e X, época em que foi incentivada a clausura estrita das monjas, os pais pressionam as filhas para que entrem para um mosteiro. Este padrão observa-se não só na Gália, mas também, embora de forma atenuada, na Itália. Algumas das principais peregrinas e andarilhas foram Maria Madalena (séc. I), Egéria (século IV), Maria Egipcíaca (344-421ou 422), Margery Kempe (1373-1438), Teresa d’Ávila (1515-1582) e Sor María de Jesús (1522-1580). 
Com o objetivo de apresentar a obra The Book of Margery Kempe, de Margery Kempe, e o Libro de las Fundaciones, de Teresa d'Ávila, mostrando como essas autoras trilharam seus longos e significativos caminhos e escreveram sobre os mesmos, buscaremos o apoio teórico de Atkinson (1983), Morrison (2000), Telles (2017) e Egido (2002), dentre outros nomes igualmente importantes.

\section{Margery Kempe: mística e peregrina}

A obra conhecida por The Book of Margery Kempe (c. 1438) tem sua autoria atribuída à mística Margery Kempe, nascida em King's Lynn (na época Bishop's Lynn), Norfolk, Inglaterra em c.1343 e falecida em c. 1435. A obra foi considerada perdida por séculos até 1934, quando foi redescoberta em um manuscrito do século XV. Foi escrita em Middle English, no dialeto de Norfolk.

O texto relata o cotidiano doméstico da autora, suas peregrinações a lugares sagrados na Europa e na Terra Santa, bem como suas conversas com Deus. A narrativa, considerada a primeira autobiografia em língua inglesa, relata as visões e as experiências de Kempe com a divindade, bem como traz um retrato bastante interessante da Idade Média inglesa:

The Book of Margery Kempe conta a história da jornada espiritual de uma mulher na Inglaterra Medieval num período de mais ou menos vinte e um anos, descrevendo sua jornada para estabelecer uma autoridade espiritual como resultado de suas conversas pessoais com Jesus e Deus. [...] Embora o texto seja escrito em terceira pessoa, é conhecido de forma geral como sendo a primeira autobiografia escrita em língua inglesa (TORN, 2008, p. 79) ${ }^{1}$.

O texto de Margery Kempe apresenta várias características sobre sua autora que podemos perceber na escrita de outras místicas seculares do período. São eles: trata-se de uma mulher da classe média inglesa medieval; foi comerciante; teve uma crise espiritual ao ter o primeiro filho; foi mística e visionária; incomodava e comovia seus contemporâneos com seus choros; recebeu influência de Brígida da Suécia, Marie d'Oignies, Angela de Foligno e Richard Rolle; peregrinou por vários locais considerados santos: Terra Santa, Roma e Bolonha (1414), Santiago de Compostela (1417), Noruega, Danzig e Aachen (1433), Abadia de Syon Inglaterra; tinha visões de Jesus Cristo, Maria e do Espírito Santo, que sugeriram que ela escrevesse um livro com suas percepções místicas. Atkinson esclarece que

\footnotetext{
${ }^{1}$ A partir desta seção do artigo, todas as citações em inglês foram traduzidas por Fernanda Cardoso Nunes, constando os originais nas notas de rodapé referidas. No original: "The Book of Margery Kempe tells the story of a woman's journey in Medieval England over a twenty-five year period, describing her quest to establish spiritual authority as a result of her personal conversations with Jesus and God. [...] Whilst the text is written in the third person, it is generally acknowledged to be the first autobiography written in English language.".
} 
Margery Kempe foi uma peregrina: na verdade, a peregrinação era um aspecto essencial de sua vocação. Ela era uma típica peregrina medieval no sentido de que ela viajou para santuários maiores e menores para venerar relíquias, celebrar a vida e a morte de Cristo e dos santos e para expiar seus pecados. A peregrinação refletia sua devoção à humanidade sagrada de Jesus e o seu desejo de compartilhar sua Paixão. Ela também visitou especialistas na vida espiritual - para buscar segurança, conversação sagrada e oportunidades especiais para a experiência religiosa (ATKINSON, 1983, p. 51) $)^{2}$.

Margery foi uma mulher impressionante. Quebrou muitos paradigmas e transgrediu modelos de feminilidade da Baixa Idade Média inglesa. Sua obra The Book of Margery Kempe impressiona a quem o lê por sua descrição dos costumes e da sociedade da época:

\begin{abstract}
Uma obra une as visões opostas de mulheres peregrinas como vistas na literatura secular e religiosa. The Book of Margery Kempe é um marco para a problemática das percepções medievais do espaço e o papel das peregrinas nisto. O gênero do Book mistura hagiografia - a influência das revelações de Brígida da Suécia é evidente ao longo da obra - autobiografia e visões (MORRISON, 2000, p. 128) ${ }^{3}$.
\end{abstract}

A autora, que percorreu os mais importantes lugares da Cristandade, deixou um relato detalhado de suas andanças e de suas experiências místicas: "Margery faz um récit do percurso, com muitos meandros e desvios, que a conduziram a si mesma, tornaram 'aquela criatura', como se designa em grande parte do relato, em Margery Kempe [...].” (TELLES, 2017, p. 27). A obra da peregrina de King's Lynn constitui um verdadeiro roteiro de viagem pelos locais sagrados que recebiam muitos peregrinos na Idade Média. O desejo por peregrinar, por conhecer os lugares onde se desenrolou todo o sofrimento vivido por Jesus em sua Paixão, é expresso logo nas primeiras páginas do livro:

Essa criatura, quando o Senhor Jesus Cristo a perdoou pelo seu pecado (como já mencionado), teve um desejo de ver os lugares que Ele nasceu, onde ele sofreu sua Paixão e onde Ele morreu, junto com outros lugares que Ele percorreu durante Sua vida e depois da Sua Ressurreição. Ao ter esses desejos, nosso Senhor a encarregou em seu pensamento, dois anos antes de ela partir, que ela fosse a Roma, Jerusalém e

\footnotetext{
${ }^{2}$ No original: "Margery Kempe was a pilgrim: indeed, pilgrimage was an essential aspect of her vocation. She was a typical medieval pilgrim in that she traveled to greater and lesser shrines to venerate relics, to commemorate the lives and deaths of Christ and the saints, and to expiate her sins. Pilgrimage reflected her devotion to the sacred humanity of Christ and her desire to share in his Passion. She also went to visit experts in the spiritual life - to seek assurance, holy conversation, and special opportunities for religious experience."

${ }^{3}$ No original: "One work unites the opposing visions of women pilgrims as seen in secular and religious literature. The Book of Margery Kempe is a touchstone for the problematic of medieval perceptions of space and the role women pilgrims play in it. The genre of the Book melds hagiography-the influence of Bridget's revelations is evident throughout the work - autobiography, and visions."
} 
Santiago, pois ela iria com muita alegria se tivesse dinheiro para ir. (KEMPE, 2015, p. 33$)^{4}$.

É importante notar que, ao desejar conhecer os lugares sagrados, imediatamente surge a voz da divindade para ordenar Margery a partir em peregrinação para os ditos sítios. Outra coisa a se ressaltar aqui é a falta de recursos para realizar a empreitada e como isso será sanado ao longo da narrativa com muitas soluções "mágicas" a surgirem pelo caminho, como pessoas que aparecem do "nada" e a ajudam com alimentos, roupas e dinheiro etc. As aventuras de Margery Kempe pelos lugares se desenvolvem num ritmo cheio de ação e movimento, para além dos muitos obstáculos que vão surgindo ao longo do enredo.

Como se sabe, as obras literárias têm na ação, no movimento, um elemento crucial no desenrolar dos seus enredos. A peregrinação, como movimento de validação e de reafirmação da fé e de si mesmo, está presente em várias obras da língua inglesa:

Similarmente, as peregrinas da literatura religiosa proclamam publicamente sua fé pelo sinal de fazer uma peregrinação. O movimento público é como o discurso público - ambos funcionam como declarações de fé. O movimento público funciona como um ato de discurso de movimento e espaço. Nos textos religiosos, peregrinas devotas são autorizadas por sua atividade de peregrinação. (MORRISON, 2000, p. 129) ${ }^{5}$.

Basta lembramos que um dos cânones da literatura inglesa medieval, escrito a partir de 1387, The Canterbury Tales (Os Contos de Cantuária) de Geoffrey Chaucer, tem o seu enredo baseado nas histórias contadas pelos peregrinos em sua visitação ao Santuário de St. Thomas à Becket em Canterbury. No caso de Margery Kempe, ela afirma sua individualidade com as várias peregrinações, pois como observa Alice Barfoot (2013, p. 3), a peregrinação é geralmente usada como uma metáfora simbólica para o movimento místico, no caso de Margery, em busca de uma maior familiaridade com os sofrimentos de Jesus Cristo.

Vale lembrar que Margery assevera que todas as suas peregrinações foram "commanded by God" (“ordenadas por Deus"), como é bastante destacado em seu livro. Ao mesmo tempo, “[...] estrutura a narrativa não seguindo ordem cronológica absoluta, mas através de sua história pessoal por espaços públicos, estranhos ou novos para ela e paralelos percursos pelos caminhos da imaginação ativa, isto é, pelo espaço entre a percepção sensorial e as categorias do intelecto.”

\footnotetext{
${ }^{4}$ No original: "This creature, when our Lord Jesus Christ had forgiven her for her sin (as written beforehand), had a desire to see those places where He was born and where He suffered His Passion and where He died, along with other holy places where He was during His life and also after His Ressurection. As she was having these desires, our Lord charged her in her mind, two years before she went, that she go to Rome, to Jerusalem, and to Santiago, for she would happily have gone but she had no money with which to go."

5 "Similarly, female pilgrims of religious literature publicly proclaim their faith by the sign of going on pilgrimage. Public movement is like public speech - both function as declarations of faith. Public movement functions as a speech act of motion or space. In religious texts, devout women pilgrims are sanctioned for their pilgrimage activity."
} 
(TELLES, 2017, p. 33). Assim, podemos inferir que a configuração espacial da narrativa tanto é experienciada sensorialmente, quanto imaginativamente pela personagem Margery, visto que as próprias visitações aos lugares desencadeiam reações intensas e percepções visuais para além de uma visão meramente material: em Belém, por exemplo, ela relata suas conversações com Maria, mãe de Jesus, na manjedoura onde o Cristo nasceu, numa dimensão espiritual: “[..] ela teve uma grande devoção, muitos discursos e conversas em sua alma como muito choro e soluços, tanto que seus companheiros peregrinos não a deixaram comer em sua companhia." (KEMPE, 2015, p. 68) ${ }^{6}$.

Como podemos constatar, a partir dessas informações, apesar de toda essa escritamovimento num sentido místico e de afirmação de sua ligação com o sagrado, Kempe, em suas primeiras peregrinações, é desacreditada e se torna motivo de medo e de chacota por parte de seus contemporâneos:

Certa feita, quanto essa criatura estava em Cantuária, na igreja entre os monges, ela foi muito repreendida e desprezada, tanto pelos monges quanto pelos padres e pelos seculares, pois ela chorou muito, quase o dia todo, tanto pela manhã quanto pela tarde também. E foi tanto que o marido dela foi embora, deixando-a sozinha como se não a conhecesse e abandonando-a entre eles, como se ela tivesse escolha, pois ela não teria mais conforto vindo dele naquele dia. (KEMPE, 2015, p. 29) 7.

Margery Kempe, em sua forma particular de interação com a divindade, era incompreendida até pelo próprio marido. Este a abandona em meio a muitas de suas andanças, deixando-a muitas vezes à mercê de situações perigosas. Em outros momentos, como observa Susan Morrison, ela, como ocorre a muitas peregrinas, é vista com desconfiança, pois muitos não acreditam que ela peregrinou realmente: “Como em muitas obras seculares que apresentam mulheres peregrinas, Kempe se orgulha de si mesma e se traja de forma berrante. Como muitas peregrinas literárias, Kempe é acusada de nunca ter participado de uma peregrinação.” (MORRISON, 2000, p. 128) ${ }^{8}$. O fato de ser uma mulher leiga, e usar roupas brancas, sinal de castidade, o que não seria conveniente religiosamente a ela que era uma mulher casada e mãe de quatorze filhos, coloca-a em muitas situações embaraçosas, chegando mesmo a ser presa por

\footnotetext{
${ }^{6}$ No original: "[...] she had great devotion, much speech, and conversation in her soul with much weeping and sobbing, so that her fellow pilgrims would not let her eat in their company."

${ }^{7}$ No original: "One time, when this creature was at Canterbury in the church amongst the monks, she was deeply despised and reproached, both by monks and priests, and by secular people, because she wept so much, nearly all day, both morning and afternoon too, and so much that her husband went away from her as if he did not know her and he left her alone amongst them, choose how she might, for she had no more comfort from him that day." ${ }^{8}$ No original: "As in many secular works featuring women pilgrims, Kempe is proud of herself and decks herself out in a gaudy way. Like many literary women pilgrims, Kempe is accused of not having actually gone on pilgrimage."
} 
heresia pelo seu comportamento excêntrico na cidade de Beverly na Inglaterra. No entanto, ao longo da jornada, a voz divina sempre a confortava e a encorajava: "E quando ela foi para Veneza, muitos de seus companheiros ficaram doentes e nosso Senhor lhe disse, 'Não tenha medo filha, ninguém morrerá no barco em que você está." (KEMPE, 2015, p. 70) 9 .

Mesmo com todas as dificuldades enfrentadas, Kempe demonstra grande disposição, tanto de corpo quanto de espírito, para continuar seus caminhos. Norma Telles ainda destaca que a peregrina inglesa se inspira na tradição das místicas medievais para ter forças para continuar. Nomes como Maria Madalena, Brígida da Suécia e Catarina de Sena aparecem nos seus escritos: “[...] genealogias que escolhe para si ao tomar uma via excêntrica com indícios de desnorteio, uma via que só se descortina durante a caminhada.” (TELLES, 2017, p. 65).

E assim, Margery Kempe vai percorrendo, através das suas peregrinações exteriores e interiores, um percurso de visões e revelações acerca de si e da experiência com a divindade. Cidades, santuários, igrejas, pessoas vão se descortinando e mostrando uma variedade de cenários que acabam por construir um imaginário muito próprio de uma mulher que teve uma vida impressionante na Baixa Idade Média inglesa. Kempe não se deixou vencer por todos os desafios que enfrentou, dentro e fora dos meios religiosos, deixando como legado uma narrativa que permanece como testemunho de uma tradição de místicas medievais que deixaram suas marcas na sociedade e na literatura de seu tempo e que ecoam até os dias de hoje.

\section{Teresa d'Ávila: andarilha e escritora}

Quase um século após Margery Kempe, surge Teresa d'Ávila (1515-1582), na Espanha, e se torna uma famosa carmelita que escreve profusamente. Notabiliza-se pelo protagonismo em vários campos de sua trajetória: funda a Ordem das Carmelitas Descalças - OCD (esse feito também se configura como uma reforma da Ordem Carmelita que, naquela época, segue a regra primitiva mitigada ${ }^{10}$ ), torna-se andarilha e escritora, apenas para citar alguns de seus principais quesitos de destaque.

\footnotetext{
${ }^{9}$ No original: "And as she went to Venice, many of her companions were really sick, and our Lord always said to her, 'Do not be afraid, daughter, no person shall die in the ship you are in."

${ }^{10}$ A chamada "regra primitiva mitigada" (aprovada pelo papa Inocêncio IV, em 01 de outubro de 1247) era a regra carmelita com menos rigor do que a da Antiga Observância, elaborada por Alberto, patriarca de Jerusalém (11491214). A Ordem das Carmelitas Descalças retoma alguns elementos do rigor primitivo e sua principal característica era o voto de pobreza, sendo este simbolizado pelo uso de sandálias, em vez de sapatos, mesmo em meio ao rigoroso frio. Dessa característica, advém a ideia de descalcez, representada no nome oficial da Ordem.
} 
A escritora trata de registrar suas fundações no chamado Libro de las Fundaciones ou, simplesmente, Fundaciones, que é uma narrativa tradicionalmente dividida em 31 capítulos ${ }^{11}$, por meio dos quais Teresa relata 15 das suas fundações de mosteiros $^{12}$, sendo 14 delas na região de Castela (Espanha) e apenas uma (a de Sevilha) na região da Andaluzia.

O Libro de las Fundaciones intercala os capítulos de teor narrativo com outros de caráter mais didático, pedagógico e doutrinário, nos quais orienta sobre a vida monástica, tanto para as monjas comuns do carmelo descalço como para as prioras, a fim de prepará-las para conduzir cada grupo de religiosas. A autora não deixa de reforçar seus ensinamentos sobre oração e regras da boa convivência, sendo os primeiros centralizados no seu Libro de la Vida.

Existe uma série de questões relacionadas à realidade apresentada no Libro de las Fundaciones e uma delas está relacionada ao conturbado momento que foi o Siglo de Oro espanhol. A obra é escrita durante os anos de maturidade de sua autora, enquanto ela ainda está fundando mosteiros, mais especificamente entre os anos de 1567 (fundação de Medina del Campo) e 1582 (fundação de Burgos e ano da morte da fundadora), uma época em que há uma efervescência cultural na Europa, de maneira geral, mas também uma forte onda de recrudescimento das perseguições inquisitoriais na Espanha. A própria Teresa d'Ávila passa por uma investigação inquisitorial, tendo o Libro de la Vida ficado por um longo tempo nas mãos do Tribunal do Santo Ofício, devido às perseguições da princesa de Eboli.

Uma das questões que sobressaem a respeito de Teresa d'Ávila, na presente discussão, além da característica de andarilha, é o fato de a autora haver empreendido um trabalho plural, tanto na produção de escritos que resultaram em transformações culturais e religiosas ou foram resultados destas, quanto no enfrentamento de desafios vários, próprios ao seu contexto de atuação.

Teresa d'Ávila não foi uma peregrina, no mesmo sentido aplicado às experiências de Margery Kempe, mas foi uma andarilha, principalmente por causa de suas fundações. Depois da fundação do Convento de San José (1562), em Ávila, além de fundar outros conventos,

\footnotetext{
${ }^{11}$ Devido ao teor narrativo do epílogo, a edição das obras completas Editorial de Espiritualidad (EDE) optou por classificar esse trecho da obra como capítulo, apresentando assim uma mudança de estrutura que produz outras possibilidades de leitura da obra teresiana em questão.

${ }^{12}$ Teresa d'Ávila fundou 17 mosteiros. No entanto, a obra destacada neste artigo traz a narrativa de apenas 15 dessas fundações, pois o mosteiro fundacional da Ordem das Carmelitas Descalças, o de São José (Ávila), tem sua inauguração narrada no Libro de la Vida, mais especificamente entre os capítulos 32 e 36. Também o Convento de San José (Granada) não consta no seu texto, pois o relato, talvez, não soasse oportuno, já que essa fundação ocorreu no ano de sua morte e foi realizada na região da Andaluzia, distante das possibilidades de acesso para Teresa d'Ávila, que estava debilitada pela velhice e enfermidades. Em Granada, Teresa foi representada por seu companheiro de ideal, Juan de la Cruz e por Ana de Jesús, registrando-se os dois como fundadores oficiais. Isso explica a razão de Granada constar no roteiro das fundações teresianas, mas não constar na obra da qual tratamos neste artigo.
} 
muitas vezes foi chamada para atender às necessidades burocráticas e de outro teor, das suas filhas espirituais, ou foi enviada para determinadas casas de pessoas seculares que requisitavam sua presença. Neste último caso, não raro, demorava-se por muitos dias, geralmente, a contragosto.

De toda a obra teresiana, é justo considerar que o Libro de las Fundaciones centraliza o aspecto andarilho de sua autora, mas não é exagero dizer que quase toda a sua obra traz esse conteúdo, pois a fundadora do carmelo descalço teve que viajar até o momento de sua morte, que aconteceu em uma cela de uma de suas fundações (Monasterio de la Anunciación de Nuestra Señora de Carmelitas Descalzas - Alba de Tormes), aos 04 de agosto de 1582, mais especificamente às 21 horas.

Não por acaso, uma das suas biografias mais importantes, realizada pela escritora e jornalista francesa Marcelle Auclair, apresenta a imagem da biografada como andarilha. Tratase de La vie de Sainte Thérèse d'Avila, la Dame Errante de Dieu (1950), cuja publicação em português recebeu o título de Santa Teresa de Ávila: a dama errante de Deus (tradução não informada na publicação). A imagem de andarilha, portanto, é uma das que marcam a memória cultural a respeito de Teresa d'Ávila. Ela é representada fartamente em pinturas, desenhos, esculturas, bem como no cinema. Como exemplo, a Figura 1 mostra uma das mais famosas esculturas, exposta na calçada do Convento da Encarnação, em Ávila.

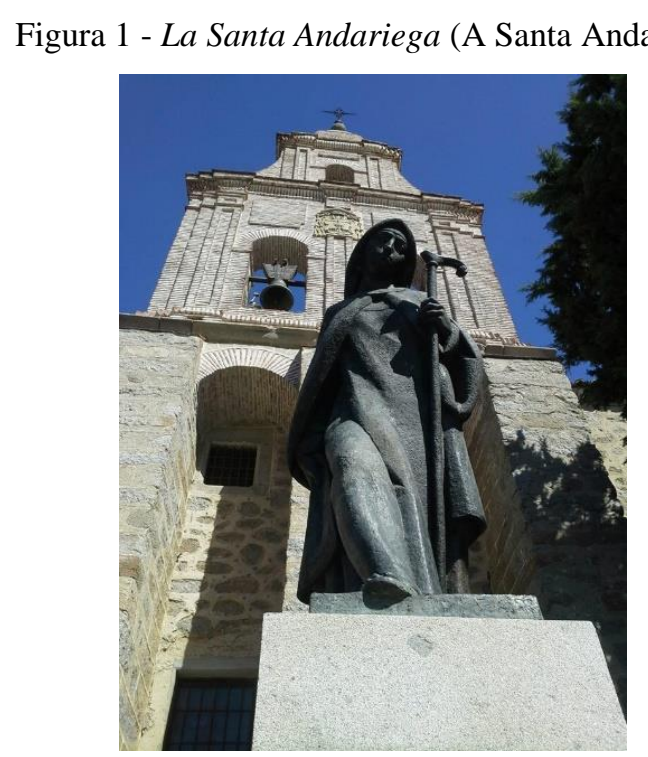

Fonte: Acervo pessoal, 2015.

Uma tônica marcante no conjunto das narrativas fundacionais de Teresa d'Ávila diz respeito aos desafios enfrentados durante as viagens empreendidas às diversas cidades onde 
fundou. Sobre isso, a autora e andarilha afirma não ser esse o quesito mais importante de seu escrito aqui em análise, o Libro de las Fundaciones. No capítulo 18 ela escreve ${ }^{13}$ :

Não ponho nestas fundações os grandes trabalhos dos caminhos, com frio, com sol, com neve, que vinha de não cessar o dia inteiro de nevar, outras de perder o caminho ${ }^{14}$, outras com grandes males e quenturas porque (glória a Deus!), de ordinário, é eu ter pouca saúde $[\ldots](\mathrm{F} 18,4)^{15}$.

Apesar dessa declaração, Teresa relata algumas dificuldades como aquela que experimentou, com sua comitiva, no caminho de Sevilha, em 1575:

Não vos deixarei de contar sobre a má hospedagem que tive para esta necessidade:
deram-nos um quartinho à telha-vã, sem janela e, se se abria a porta, enchia-se todo
de sol (haveis de ver que por lá não é como o de Castela, senão muito mais importuno).
Fizeram-me deitar em uma cama, que eu teria achado melhor deitar no chão porque
era de umas partes tão alta e de outras tão baixa, que eu não sabia como poderia ficar
porque parecia feita de pedras agudas. Que coisa é a doença! Com saúde, tudo é fácil
sofrer! Enfim, tive por melhor levantar-me e que partíssemos, que melhor me parecia
sofrer o sol do campo do que o daquele quartinho. $(\mathrm{F} 24,8)^{16}$.

Esses relatos sobre os desafios próprios dos percursos trazem, nas entrelinhas, entre outras questões, a marcação de que a fundadora realizou seu projeto de reforma com destemor e fortaleza, superando as más condições de variada natureza. Os meios de transporte eram diversos, como o carro coberto por um toldo e puxado por cavalos, a liteira, a carroça e até mesmo o lombo de um burro (EGIDO, 2002). A reconhecida imagem teresiana de andarilha, portanto, é menos literal do que ilustrativa. Basta que consideremos as longas distâncias de seus percursos, nem sempre restritos à sua região (Castela), o que jamais se poderia percorrer a pé.

No decorrer das Fundaciones também constam narrativas sobre as condições de chegada aos lugares onde os conventos são fundados. Em seu primeiro deslocamento de Ávila (para Medina del Campo), por exemplo, chega ao destino por volta da meia-noite e, sem dar conta dos hábitos do lugar, percebe que, por pouco, ela e sua comitiva haviam escapado de um

\footnotetext{
13 Todas as traduções dos textos teresianos presentes neste artigo são de autoria de Maria Graciele de Lima. As referências das citações em espanhol seguem o modelo canônico aplicado às obras teresianas.

${ }^{14}$ Conforme Teófanes Egido (2002), esta era uma das principais dificuldades dos/as viajantes da época. Teresa e sua comitiva costumavam usar dois guias de viagem escritos por Juan Villuga e Alonso de Meneses.

${ }^{15}$ No original: "No pongo en estas fundaciones los grandes trabajos de los caminos, con fríos, con soles, con nieves, que venía vez no cesarnos en todo el día de nevar, otras perder el camino, otras con hartos males y calenturas - porque, gloria a Dios, de ordinario es tener yo poca salud [...]"

${ }^{16}$ No original: "No os dejaré de decir la mala posada que huvo para esta necesidad; fue darnos una camarilla a teja vana; ella no tenía ventana, y si se abría la puerta, toda se henchía de sol (habéis de mirar que no es como el de Castilla por allá, sino muy más importuno); hiciéronme echar en una cama, que yo tuviera por mejor echarme en el suelo, porque era de unas partes tan alta y de otras tan baja, que no sabía cómo poder estar, porque parecía de piedras agudas; iqué cosa es la enfermedad, que con salud todo es fácil sufrir! En fin, tuve por mejor levantarme, y que nos fuésemos, que mejor me parecía sufrir el sol del campo que no de aquella camarilla."
} 
possível ataque de touros, pois os animais que seria postos para correr no dia seguinte haviam sido presos há pouco tempo (F 24, 6).

Por último, há um elemento duplo fundamental a ser considerado no que tange ao contexto de elaboração do Libro de las Fundaciones. Refere-se à idade e às condições de saúde da autora, quando no processo de escrita, e ao fato de que o texto foi elaborado enquanto a maioria dos acontecimentos narrados se desenrolavam. Esse duplo elemento também pode ser incluído dentre as particularidades desafiadoras que compuseram a jornada de fundações.

Evidentemente, não apenas de reveses se constituem a história e a narrativa dos caminhos teresianos. A autora e andarilha também recebeu muito apoio simbólico e material de muitas pessoas importantes de seu tempo, de vários setores da sociedade, tanto religiosos como seculares. Teve as devidas licenças para fundar meios de transportes providenciados por apoiadores/as (destaque-se o caso emblemático do apoio de D. Luisa de la Cerda) e recebeu doações de imóveis, nem sempre em condições favoráveis, mas que puderam ser adaptados posteriormente.

Diferentemente de Margery Kempe, Teresa não peregrinou por lugares tão diversos e seus cenários foram todos espanhóis, a maioria castelhanos. Mas uma aproximação dessas duas místicas e o conhecimento, mesmo resumido, de seus empreendimentos logo mostram que ambas desbravaram mais do que caminhos geográficos, pois, salvas as devidas particularidades biográficas e contextuais, saíram dos condicionamentos mais comuns às mulheres suas contemporâneas.

\section{Considerações finais}

Margery Kempe e Teresa d'Ávila percorreram longas distâncias geográficas a fim de realizar uma importante fração de suas jornadas religiosas e elas escreveram sobre essa profunda experiência. Podemos dizer que a existência de suas obras, bem como a conservação destas até os dias atuais, fez com que nos tornasse possível reconhecer uma tradição que nos remete a Egéria e a outras mulheres que escreveram, peregrinaram ou se tornaram andarilhas, ao longo do Medievo, principalmente.

Nossa reflexão, no presente contexto, atinge parte da plurissignificância que está contida para além das linhas do The Book of Margery Kempe e do Libro de las Fundaciones. No mínimo, podemos considerar que há uma poderosa e labiríntica metáfora que atravessa o peregrinar, o andar e o fundar instituições religiosas para mulheres: sair, abrir/trilhar caminhos, ocupar territórios geográficos e simbólicos, tornar-se autora de livros, deixando textos que 
atravessam os séculos, é uma imensa atuação em um período marcado por perseguições religiosas e outras, comumente motivadas pela misoginia.

Sob esse olhar, se nossas lentes se voltarem para o contexto medieval, as obras de Kempe e de Teresa ${ }^{17}$ propõem um novo traçado da memória coletiva, muito mais abrangente, pois inserem as duas autoras em uma história de produção literária e religiosa que pertence a uma imensa tradição, como insistimos em dizer. Dentro dela, estão todas as místicas, peregrinas, fundadoras, andarilhas e intelectuais cujos escritos nos permitem reconstruir caminhos históricos de implicação tanto religiosa, quanto estética, como é o enfoque deste artigo. As leituras continuam sempre, pois ainda estamos começando a descobrir a imensidão das obras dessas peregrinas, andarilhas e autoras.

\section{Referências}

ATKINSON, Clarissa W. Mystic and Pilgrim. The Book and the World of Margery Kempe. Ithaca: Cornell University Press, 1983.

AUCLAIR, Marcelle. Santa Teresa de Ávila: a dama errante de Deus. 4 ed. Braga: Editorial A. O., 2001.

EGIDO, Teófanes. Libro de las Fundaciones. In: BARRIENTOS, Alberto (dir.).

Introducción a la lectura de Santa Teresa. 2. ed. Madrid: EDE, 2002.

FRANÇA, Susani Silveira. Peregrinos e centros de peregrinação. In: FRANÇA, Susani Silveira Lemos; NASCIMENTO, Renata Cristina de Sousa; LIMA, Marcelo Pereira. Peregrinos e Peregrinação na Idade Média. Petrópolis: Editora Vozes, 2017. p. 9-71.

KEMPE, Margery. The Book of Margery Kempe. Tradução de B.A. Windeatt. Londres: Penguin Books, 1994.

LE GOFF, Jacques. Uma longa Idade Média. Tradução de Marcos de Castro. 2. ed. Rio de Janeiro: Civilização Brasileira, 2010.

MORRISON, Susan. Women Pilgrims in Late Medieval England. Londres: Routledge, 2000 .

RÉGNIER-BOHLER, Danielle. Vozes literárias, vozes místicas. In: DUBY, Georges; PERROT, Michelle. História das Mulheres: a Idade Média. Tradução de Ana Losa Ramalho et al. 6 ed. Porto: Edições Afrontamento, 1990. p. 517-591.

TELLES, Norma. O livro de Margery Kempe. In: Mulheres viajantes: sete jornadas insólitas. São Paulo: Annablume, 2017.

${ }^{17}$ O Medievo ao qual Teresa d'Ávila pertence é aquele pensado por Le Goff (2010), muito mais pautado nos valores culturais do que nos recortes cronológicos. O que mais liga a obra teresiana aos valores medievais é a chamada Mística apofática vivida e tratada em seus escritos. 
TERESA DE JESUS, Santa. Obras Completas. 4. ed. Madrid: La Editorial Catolica, 1915. BAC 212. Transcrição, introduções e notas de Efrén de la Madre de Dios, OCD e Otger Steggink, O. Carm.

TERESA DE JESUS, Santa. Obras Completas. 6 ed. Burgos: EDE, 2016.

TORN, Alison. Margery Kempe: Madwoman or Mystic - A Narrative Aproach to the Representation of Madness and Mysticism in Medieval England. In: TORN, Alison. Narrative and Fiction: an Interdisciplinary Approach. Huddersfield: University of Huddersfield, 2008.

Recebido em: 28/07/2020 Aceito para publicação em: 10/09/2020 